\title{
Evaluation of an Empathy Training Program to Prevent Emotional Maladjustment Symptoms in Social Professions
}

\author{
Tobias Altmann, Victoria Schönefeld, Marcus Roth \\ Psychological Institute, University Duisburg-Essen, Essen, Germany \\ Email: tobias.altmann@uni-due.de
}

Received 30 October 2015; accepted 17 November 2015; published 20 November 2015

Copyright (C) 2015 by authors and Scientific Research Publishing Inc.

This work is licensed under the Creative Commons Attribution International License (CC BY). http://creativecommons.org/licenses/by/4.0/

(c) (i) Open Access

\begin{abstract}
This study examined the impact of a 4-day empathy training program for social professions. The major focus of the training was to enhance reflected empathic behavior as a resource in emotionally tense situations by strengthening self-other differentiation and emotional self-acceptance. It was hypothesized that maladjustment symptoms such as depressiveness and irritation would decline as a consequence. The sample analyzed in this randomized control study evaluating the training program was comprised of 319 health care trainees at the graduate level (intervention group $n=147$, control group $n=172$ ). Longitudinal follow-up data were collected before and 3 months after the training. Measures of emotional competences and maladjustment symptoms were taken. Results showed significant change in emotional self-acceptance, resilience, emotional self-perception, self-other-differentiation, irritation, and psycho-social maladjustment symptoms in the intervention group compared with the control group. Self-other differentiation was found to be a small yet significant mediator.
\end{abstract}

\section{Keywords}

Empathy, Health Care, Intervention, Nonviolent Communication, Training Evaluation

\section{Introduction}

Empathy is considered a central resource in social professions such as therapy, counseling, and especially health care (Brunero, Lamont, \& Coates, 2010; Hojat, 2007). Training programs to enhance empathy are therefore understandably frequently implemented in the field (Brunero et al., 2010; Stepien \& Baernstein, 2006). Besides the fact that these programs are seldom evaluated according to the standards of psychological science (Butters, 
2010), most programs try to enhance empathy without considering the negative consequences that the empathic sharing of emotions can have (e.g., depression; Carré, Stefaniak, D’Ambrosio, Bensalah, \& Besche-Richard, 2013; Corcoran, 1989; Thoma et al., 2011), especially in the social professions (Åström, Nilsson, Norberg, Sandman, \& Winbald, 1991; Thomas, 2013).

Self-other differentiation being the ability to keep the emotions of another person separate from one's own emotions is a significant factor in empathy (Altmann \& Roth, 2013), but it is usually considered simply as a given in empathy models (Decety \& Jackson, 2006). As a consequence, many empathy training programs tend to ignore this variable and promote a rather undifferentiated version of empathy aimed at increasing empathy "as such" without considering the functional and dysfunctional aspects of the interactional empathy process.

In this paper, we discuss dysfunctional aspects of empathic behavior to explain the relation between this undifferentiated or "unreflected" empathy and long-term maladjustment symptoms such as depressiveness. A training program to reduce dysfunctional empathic behaviors through self-other differentiation is presented and evaluated.

\subsection{Empathy and Dysfunctional Empathic Behavior}

Empathy has been defined in many ways, such as feeling with (Hoffman, 2000), feeling into (Kohut, 1984), understanding (Steins \& Wicklund, 1993) another person, and responding to him or her in a certain way (Kunyk \& Olson, 2001). Based on this multitude of concepts, Marshall, Hudson, Jones, and Fernandez (1995) as well as Altmann and Roth (2013), among others, showed how the most frequently described aspects of empathy (cognitive and affective empathy as well as conceptions as a trait, temperament, ability, and skill; e.g., Davis, 1983; Gerdes, Segal, \& Lietz, 2010; Preston \& de Waal, 2002; Singer, 2006), can be integrated into a comprehensive empathy model. The inner process of empathy is described as a sequence of 1) perceiving the other person's emotional information, 2) generating a mental model or mental representation of the other person's situation, 3) generating an empathic emotion similar to that perceived to be felt by the other person, and 4) responding to the other person.

Although empathy is commonly associated with socially desirable variables such as altruistic behavior (Batson \& Shaw, 1991), relationship satisfaction (Long, Angera, \& Hakoyama, 2008), and leadership efficacy (Kellett, Humphrey, \& Sleeth, 2002), current studies also report correlations with negative outcomes such as depressiveness (Thoma et al., 2011) and burnout (Bragard, Etienne, Merckaert, Libert, \& Razavi, 2010; Lee, 2010).

As an explanation for this relation, Altmann and Roth (2013) suggest the Empathic Short Circuit (ESC) as a form of (dysfunctional) empathic behavior with negative outcomes. The ESC can best be described with an example:

Especially in emotionally tense situations, such as when a good friend shares his sad story about an awful misfortune with his girlfriend, the empathically transferred emotion is obviously unpleasant. If the listener clearly distinguishes between her own emotions and the emotions that have been empathically aroused in her, she can share the experience with her friend and feel with him without losing her own emotional stability. If, however, the listener does not distinguish clearly enough, she will experience the unpleasant feeling triggered by her friend's narration as her own (the experience of stress when seeing others in unpleasant situations has been discussed as personal distress by e.g. Batson, Fultz, \& Schoenrade, 1987; Decety \& Lamm, 2009; Thomas, 2013). Moreover, since the listener is unable to change her friend's situation, she is thus unable to control her own emotional situation. A simple and effective way to regain control of the situation and rid herself of the unpleasant emotion would be to change her mental representation of her friend's situation. Instead of pain and sorrow, she could remodel the representation of her friend into one in which he is being whiny and oversensitive. A plausible reaction would now be to cut the interaction short and thus sever the empathic connection by invalidating the emotion or severity of the friend's situation. Evaluative remarks such as "It's not that bad," "That's no reason to cry, I had it worse when...," or "Maybe it’s for the better," are typical invalidating examples.

The need to respond in such a way may result from a weak (or situationally weakened) self-other differentiation, comparable to losing "the 'as if' quality” described by Rogers (1957: p. 99). Empathic short circuit responses are a way to end or escape this emotionally threatening or destabilizing empathic interaction by eliminating the potential of the situation — just as an electrical short circuit eliminates the electrical potential of a circuit.

Following Altmann and Roth (2013), this kind of unreflected empathic reaction may lead to an accumulation 
of emotional exhaustion, dissatisfaction, and low-quality social interactions. This, in turn, may account for a variety of maladjustment symptoms, among which are the indistinct symptoms of depressiveness, irritation, social insecurity, anxiety, or psychosomatic symptoms. This is especially the case in social professions as they involve frequent interactions in often emotionally tense settings (Åström et al., 1991; Lamm, Batson, \& Decety, 2007). Nurses, in particular, work in an environment that requires a great deal of emotional responsiveness and involves high emotional pressure (Henderson, 2001; Hojat, 2007) because patients in severe situations depend on nurses as perhaps their only readily available interaction partners. Self-other differentiation as the basis for an accurate mental representation enables reflective, functional empathic behavior (Batson et al., 1987) and prevents empathic short circuit reactions.

\subsection{Training Functional Empathy with Nonviolent Communication}

On the basis of the ideas above, we believe that empathy training programs for social professions should focus on increasing self-other differentiation as a key resource to guard against dysfunctional empathic reactions and thereby to prevent emotional exhaustion and maladjustment. This is especially relevant as the resulting symptoms are difficult to influence directly (Duquette, Kérowc, Sandhu, \& Beaudet, 1994). Consequently, we developed a training program to prevent Empathic Short Circuit reactions in the everyday work of social professions by strengthening self-other differentiation.

We found that the concept best suited to realize this objective was Nonviolent Communication (NVC) as developed by Rosenberg (Rosenberg \& Molho, 1998). NVC is a 4-step communication process in which a person's observations, feelings, needs, and requests are to be shared in a nonviolent and validating way. Conversely, analyses, interpretations, and evaluations of the other person are believed to reduce the quality of an interaction (for a detailed description, see Rosenberg, 1999, 2012). By suggesting a dual focus of attention on both the other person and on one's self, NVC promotes a clear distinction between the feelings and needs of one's counterpart and one's own feelings and needs, i.e. self-other differentiation.

The training is designed to be implemented across four consecutive days. Day 1 is about understanding what empathy is, how it is an inevitable part of everyday interactions, how unreflected empathic acting can lead to Empathic Short Circuits (ESCs), and the consequences of ESCs. Day 2 focuses on understanding the basics of NVC with practical units to incorporate tools such as the feelings and needs inventories. On Day 3, the application of NVC in interactions is practiced step-by-step in simple to complex settings. On Day 4, a complex example case is practiced in a role play setting where the various aspects of the training are applied and put to the test. Goals and example exercises for each training day are displayed in Table 1.

\subsection{Hypotheses}

As the training program focuses primarily on emotional self-reflection, especially in emotional tense situations, we expected a general increase in emotional competences for the intervention group compared with the control group. This includes the ability to recognize, accept, and clearly identify one's own emotions and the emotions of others as well as the ability to act positively even in emotionally stressful or tense situations (resilience).

As a result of the training, we expected the intervention group to experience an increase in self-other differentiation, thereby reducing the negative load of tense or otherwise negative emotions derived from empathy. This, in turn, was expected to lead to a reduction in psychosomatic symptoms and a decline in maladjustment, although these issues were not directly addressed in the training.

Consequently, we predicted that the change in these maladjustment indicators would be mediated by the change in self-other differentiation.

\section{Method}

\subsection{Sample and Procedure}

We evaluated the training program in a randomized control group design. The sample comprised nursing trainees at graduate level, i.e. the final qualification stage before certification. Subjects had a mean working time experience of 65 weeks prior to the intervention which is equivalent to 1.5 years fulltime. 
Table 1. Overview of the training program for reflective empathy.

\begin{tabular}{|c|c|c|}
\hline Training Day & Major Goals & Exemplary Exercises \\
\hline 1 & $\begin{array}{l}\text { - } \quad \text { involvement in the topic } \\
\text { knowledge of the theoretical bases of empathy and } \\
\text { the Empathic Short Circuit } \\
\text { - reflection of individual empathic acting }\end{array}$ & $\begin{array}{l}\text { - collecting associations with empathy after viewing a film } \\
\text { clip with contagious laughter } \\
\text { - mutual interviewing about recent emotional events and } \\
\text { discussing empathic reactions }\end{array}$ \\
\hline 2 & $\begin{array}{l}\text { - knowledge of the four steps and differentiations of } \\
\text { Nonviolent Communication (NVC) } \\
\text { ability to formally use these four steps to rephrase } \\
\text { individual messages }\end{array}$ & $\begin{array}{l}\text { - differentiating exemplary sentences into violent vs. } \\
\text { nonviolent language } \\
\text { using both the feelings and needs inventory to specify } \\
\text { typical messages by coworkers and patients as well as one's } \\
\text { own messages }\end{array}$ \\
\hline 3 & $\begin{array}{l}\text { - insight into the experience of being fundamentally } \\
\text { understood and the ability to promote this } \\
\text { experience in others by using the NVC pattern } \\
\text { ability to spontaneously apply the NVC pattern in } \\
\text { conversations with others and for emotional } \\
\text { self-clarification in or after emotionally intense } \\
\text { situations }\end{array}$ & $\begin{array}{l}\text { - having an argument about an actual disagreement first } \\
\text { spontaneously and then by using the process of feedback to } \\
\text { ensure that each single argument is truly understood before } \\
\text { stating one's counterargument } \\
\text { - rephrasing another participant's neutrally told story by } \\
\text { filling it with assumed emotions and needs } \\
\text { - retelling one's own story with a focus on emotions and } \\
\text { unfulfilled needs }\end{array}$ \\
\hline 4 & $\begin{array}{l}\text { - ability to use the NVC pattern in a complex } \\
\text { scenario similar to the actual work setting with the } \\
\text { dual focus on the experience of the other person } \\
\text { and on one's own experience } \\
\text { critical look back on the training and individual } \\
\text { conclusions about the opportunities and limitations } \\
\text { of NVC in practice }\end{array}$ & $\begin{array}{l}\text { - example case as a role play taken from an actual situation } \\
\text { with the responsibility of producing a positive outcome (i.e., } \\
\text { the compliance of the patient) placed solely on the } \\
\text { participant } \\
\text { discussion of pros and cons of the NVC pattern and its } \\
\text { applicability }\end{array}$ \\
\hline
\end{tabular}

The four day training program was administered by two out of four expert trainers in each training of the intervention group to ensure optimal teaching and supervision during small group exercises. All trainings were integrated into the qualification curriculum. The control group participants received a placebo training with no particular reference to empathy.

Data were collected at two measurement points (paper-pencil) with an average of 3.3 months between the initial and follow-up measurements. Initial $t_{0}$ measures for the intervention group were taken right before the training. The trainings and $t_{1}$ post measurements were scheduled so that both the intervention group and the control group had at least 6 weeks of fulltime work in a hospital in between (as part of the nursing qualification curriculum). This time of practice after the training was deemed necessary for the participants to be able to apply the learned principles, allowing the training effects to be realized. Figure 1 illustrates the design.

The total sample comprised $N=448$ subjects. Of these, $n=210$ were randomly assigned to the intervention group (nine training groups with 19 to 28 participants each) and $n=238$ to the control group. Subjects in the intervention group who did not take part in every training day and were not present at each measurement occasion were excluded. Control group participants were excluded if they participated at only one measurement point. The final sample consisted of 147 subjects in the intervention group and 172 subjects in the control group. Participants' mean age in the intervention group was $M=22.2$ years $(S D=2.5)$; in the control group, $M=21.6$ years $(S D=2.6)$. The samples were $83.0 \%$ and $81.4 \%$ female in the intervention and control groups, respectively.

\subsection{Measures}

German versions of the measures were administered. For calculating Cronbach's alphas the combined samples of intervention and control groups at the first (pre) measurement point were used.

The Emotional Competence Questionnaire by Rindermann (2009) measures emotional competence and emotional intelligence with a 5-point Likert scale ranging from 1 (strongly disagree) to 5 (strongly agree). The two subscales emotional self-perception (Cronbach's $\alpha=0.90,15$ items, e.g., “Sometimes I'm sad without knowing why") and perception of emotions in others (Cronbach's $\alpha=0.91,17$ items, e.g., "When I'm on the phone with a friend, I can understand what he's feeling”) were used. 


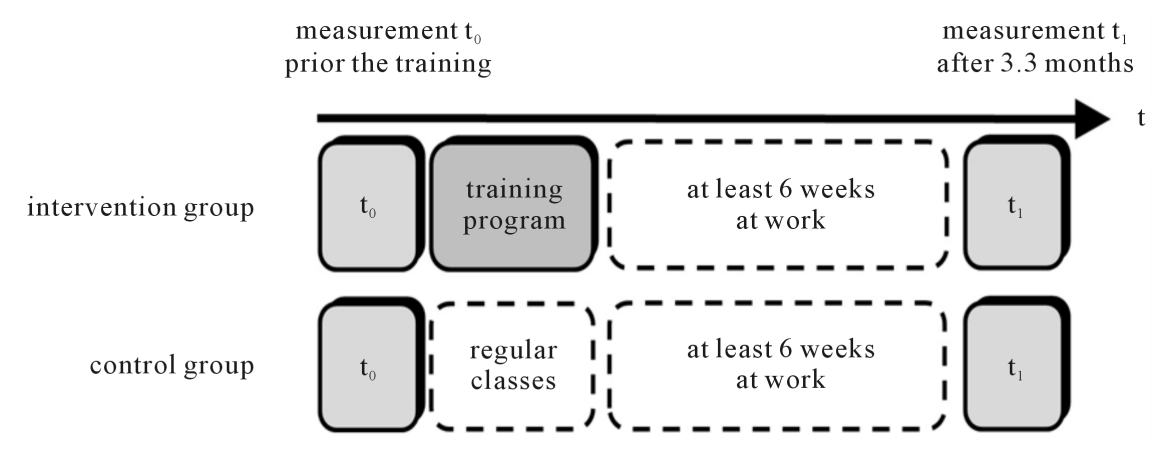

Figure 1. Study design with two experimental groups and two points of measurement.

The Self-Report Measure for the Assessment of Emotion Regulation Skills by Berking and Znoj (2008) measures the constructive handling of negative or burdensome emotions. Three out of nine subscales were used in this study, each measured with three items and a 4-point Likert scale ranging from 1 (not at all) to 4 (almost always): emotional self-acceptance (Cronbach's $\alpha=0.71$, e.g., "In recent weeks, I was able to accept even negative emotions") emotional clarity (Cronbach's $\alpha=0.70$, e.g., "In recent weeks, I knew well how I was feeling in that moment"), and resilience (Cronbach's $\alpha=0.72$, e.g., "In recent weeks, I felt capable of coping even with intense negative emotions").

The Irritation Scale (Mohr, Müller, Rigotti, Aycan, \& Tschan, 2006) measures mental and emotional job strain, rumination, and psychic exhaustion using a 7-point Likert scale ranging from 1 (does not describe me at all) to 7 (describes me quite accurately). The instrument differentiates between the subscale cognitive irritation (Cronbach's $\alpha=0.79$, three items, e.g., "Even when I'm on holiday, I think about problems at work") and emotional irritation (Cronbach's $\alpha=0.80$, five items, e.g., "If others talk to me, I react grumpily at times").

The Involvement scale by Büssing and Perrar (1992) (Cronbach's $\alpha=0.49$, three items, e.g., "In many respects, I feel similar to my patients") is a measure of lacking self-other differentiation. A 5-point Likert scale ranging from 1 (only slightly/only rarely) to 5 (very strongly/very often) was used. The low internal consistency seems to be a common problem of the scale and will be considered in the discussion.

The Symptom Checklist-90- $R$ by Derogatis (1977; cf. Franke, 1995) is a questionnaire for measuring different kinds of psychosomatic and physical strain and the impairment that results from them. Participants had to indicate the extent to which they have experienced various symptoms during the previous 7 days using a 5-point Likert scale ranging from 0 (not at all) to 4 (very strongly). We selected four of the nine subscales to use in the present study: anxiety (Cronbach's $\alpha=0.86,10$ items, e.g. "trembling”), depression (Cronbach's $\alpha=0.90,13$ items, e.g., "likely to cry”), somatization (Cronbach's $\alpha=0.85,12$ items, e.g., "headache”), and interpersonal insecurity (84, nine items, e.g., "feeling inferior to others"). Based on the results of principal component analyses, the four subscales could be subsumed into one global factor (Cronbach's $\alpha=0.96$ ) explaining $74.5 \%$ of the variance. Loadings on this factor varied between $\mathrm{a}=0.81$ and 0.89 . Because the analysis suggested a single factor, it was used as a combined indicator of psychosomatic and/or maladjustment symptoms which we called global symptom score.

\subsection{Statistical Analysis}

To analyze the efficacy of the treatment, we calculated a repeated measures MANOVA with the repeated measures factor time (pre vs. post measurement) and the between-person factor condition (intervention vs. control group) with all dependent variables in a combined multivariate model to account for the correlations between the dependent variables and calculated univariate models to estimate the effects of each dimension. Significant interaction effects between the factors time and condition would indicate that the respective variable showed a different developmental pattern as a result of the training.

As a measure of effect size, we calculated $\hat{\delta}_{I C}$ for intervention versus control group designs by Becker (1988). It can be interpreted similar to Cohen's (1988) $d$ such that effects greater than 0.20 are considered to be clinically relevant (Kimber, Sandell, \& Bremberg, 2007). A positive $\hat{\delta}_{I C}$ value indicates a stronger increase in the variable in the intervention group compared with the change in the control group and vice versa. 


\section{Results}

Displayed in Table 2 are descriptive results for both the intervention and control groups during the pre and post measurement points.

\subsection{Effects of the Training Program}

As described in the method section above, a positive $\hat{\delta}_{I C}$ value as an effect size for the intervention effect in the repeated measures MANOVA (interaction of time $\times$ condition) indicates a stronger increase in the dependent variables in the intervention group compared with the change in the control group and vice versa. The results are presented in Table 3.

The RM-MANOVA showed a significant interaction of time with condition on the outcome variables. Using Pillai's trace, the interaction effect was $V=0.11, F(18,300)=2.08, p=0.007$. Using Roy's largest root, the result is quite similar with $\Theta=0.13, F(18,300)=2.08, p=0.007$.

As indicated by the univariate tests (see Table 3), we found a significantly stronger increase in the intervention group compared with the control group for the dimensions emotional self-perception, emotional self-acceptance, emotional clarity, and resilience, as hypothesized. Likewise, we found significantly stronger declines in the intervention group compared with the control group for the dimensions of maladjustment, i.e., emotional irritation, involvement, and the global symptom score, as hypothesized.

No significant differences over time were found between the two groups on the dimensions perception of emotions in others and cognitive irritation.

Figure 2 and Figure 3 display the change over time in the two experimental groups.

\subsection{Self-0ther Differentiation as a Mediator}

The mediation procedures by Baron and Kenny (1986), the Sobel (1982) test of the indirect effect, and the kappa squared $\left(\kappa^{2}\right)$ effect size by Preacher and Kelley (2011) were calculated. $\kappa^{2}$ measures the strength of the indirect effect in relation to the effect size that the specific design could maximally produce and can take on values between 0 and 1 , where 0.01 is generally considered to be a small, 0.09 a medium, and 0.25 a large effect.

Table 2. Descriptive statistics for every dependent variable by the factors time (pre and post measurement) and condition (intervention and control group).

\begin{tabular}{|c|c|c|c|c|c|c|c|c|}
\hline & \multicolumn{4}{|c|}{ pre measurement } & \multicolumn{4}{|c|}{ post measurement } \\
\hline & \multicolumn{2}{|c|}{ IG } & \multicolumn{2}{|c|}{ CG } & \multicolumn{2}{|c|}{ IG } & \multicolumn{2}{|c|}{ CG } \\
\hline & $M$ & $S D$ & $M$ & $S D$ & $M$ & $S D$ & $M$ & $S D$ \\
\hline \multicolumn{9}{|c|}{ Emotional Competence Questionnaire } \\
\hline Emotional self-perception & 3.47 & 0.66 & 3.46 & 0.65 & 3.54 & 0.72 & 3.39 & 0.66 \\
\hline Perception of emotions in others & 3.88 & 0.45 & 3.89 & 0.46 & 3.86 & 0.51 & 3.80 & 0.49 \\
\hline \multicolumn{9}{|l|}{ Irritation } \\
\hline Cognitive irritation & 3.15 & 1.35 & 3.30 & 1.55 & 2.81 & 1.41 & 3.17 & 1.56 \\
\hline Emotional irritation & 2.78 & 1.12 & 2.89 & 1.25 & 2.64 & 1.14 & 3.06 & 1.31 \\
\hline Involvement (inverted SOD) & 1.84 & 0.63 & 1.89 & 0.63 & 1.75 & 0.60 & 2.03 & 0.69 \\
\hline \multicolumn{9}{|l|}{ Emotion Regulation Skills } \\
\hline Emotional clarity & 3.49 & 0.58 & 3.44 & 0.54 & 3.53 & 0.54 & 3.32 & 0.66 \\
\hline Emotional self-acceptance & 3.33 & 0.61 & 3.32 & 0.55 & 3.39 & 0.60 & 3.19 & 0.69 \\
\hline Resilience & 3.15 & 0.68 & 3.17 & 0.59 & 3.24 & 0.65 & 3.01 & 0.67 \\
\hline \multicolumn{9}{|l|}{ Symptom Checklist-90-R } \\
\hline Global symptom score & 0.58 & 0.46 & 0.70 & 0.60 & 0.55 & 0.48 & 0.80 & 0.70 \\
\hline
\end{tabular}

Note: IC Intervention Group, CG Control Group, SOD self-other differentiation. 
Table 3. Univariate results from the repeated measures MANOVA for the interaction of time (pre vs. post) and condition (intervention vs. control) with estimates of effect size.

\begin{tabular}{|c|c|c|c|}
\hline Dimension & $F$ & $p$ & $\hat{\delta}_{I C}$ \\
\hline \multicolumn{4}{|c|}{ Emotional Competence Questionnaire } \\
\hline Emotional self-perception & $5.99^{*}$ & 0.015 & 0.22 \\
\hline Perception of emotions in others & 2.00 & 0.159 & 0.14 \\
\hline \multicolumn{4}{|l|}{ Irritation } \\
\hline Cognitive irritation & 1.99 & 0.160 & -0.14 \\
\hline Emotional irritation & $6.85^{* *}$ & 0.009 & -0.26 \\
\hline Involvement (inverted SOD) & $9.54^{* *}$ & 0.002 & -0.37 \\
\hline \multicolumn{4}{|l|}{ Emotion Regulation Skills } \\
\hline Emotional clarity & $5.73^{*}$ & 0.017 & 0.28 \\
\hline Emotional self-acceptance & $7.89^{* *}$ & 0.005 & 0.34 \\
\hline Resilience & $10.90^{* *}$ & 0.001 & 0.39 \\
\hline \multicolumn{4}{|l|}{ Symptom Checklist-90-R } \\
\hline Global symptom score & $5.45^{*}$ & 0.020 & -0.23 \\
\hline
\end{tabular}

Note: SOD self-other differentiation. F-values using the Greenhouse-Geisser procedure. $\hat{\delta}_{I C}$ effect size measure by Becker (1988): positive values indicate a higher change over time for the intervention group compared with the control group. ${ }^{*} p<0.05 .{ }^{* *} p<0.01$.
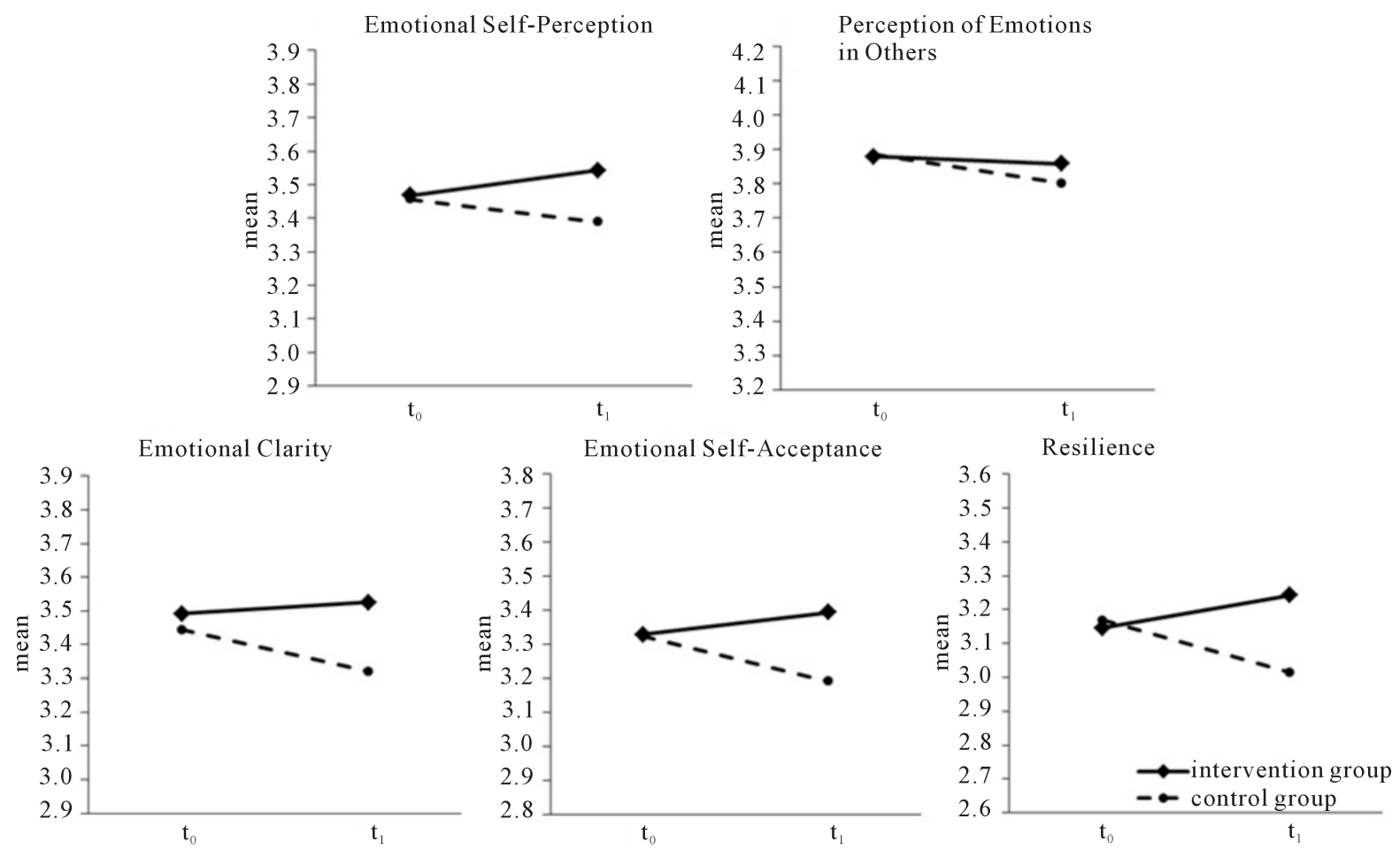

Figure 2. Mean change in outcome variables indicating emotional competences for the intervention group compared with the control group for pre training $\left(\mathrm{t}_{0}\right)$ versus three months after training $\left(\mathrm{t}_{1}\right)$.

Mediation effects were tested for the two maladjustment variables emotional irritation and the global symptom score as no training effect was observed for cognitive irritation. As shown in Figure 4 and Figure 5, the regression coefficients decreased in both outcome variables when the mediator variable was included in the model, 

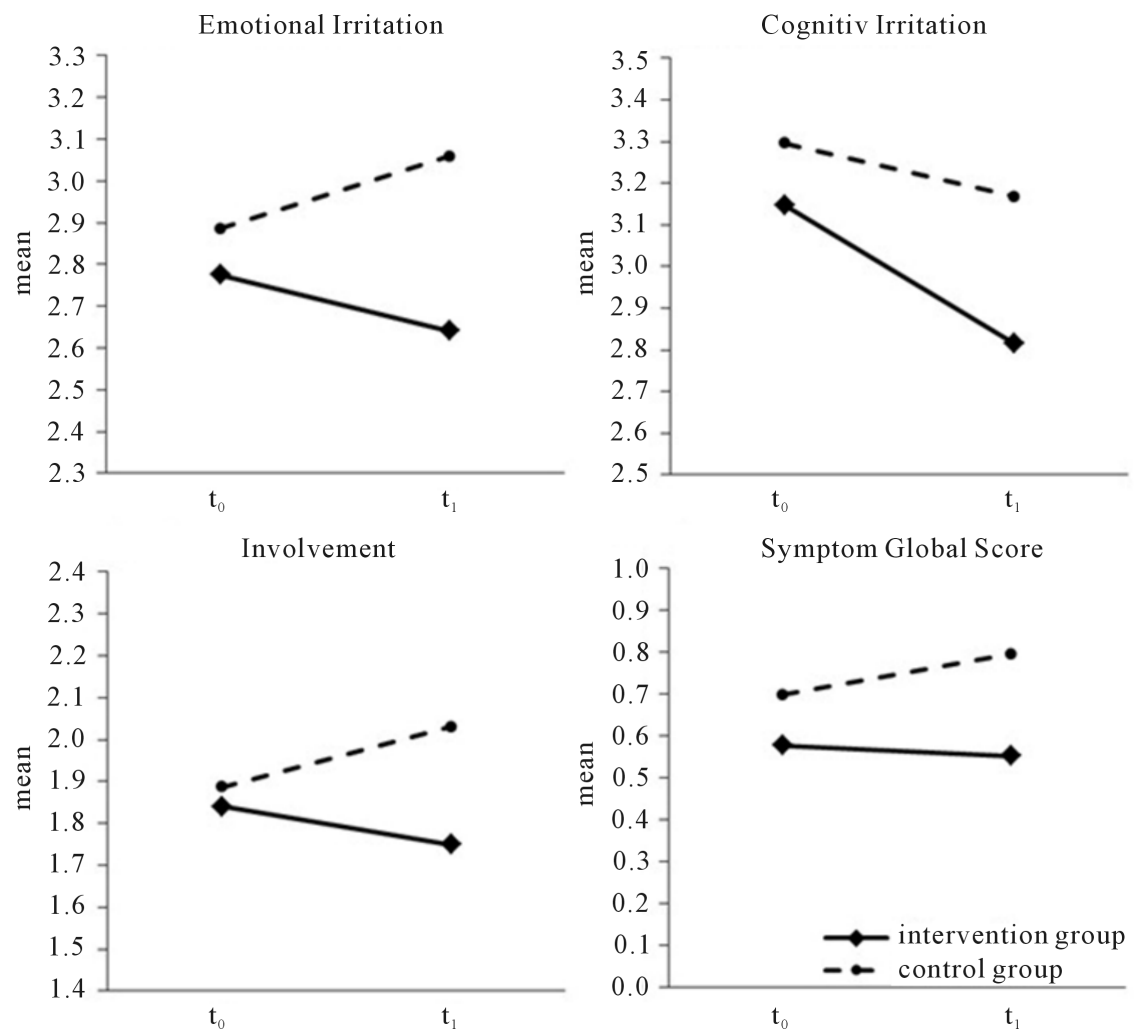

Figure 3. Mean change in outcome variables indicating maladjustment symptoms for the intervention group compared with the control group for pre training $\left(\mathrm{t}_{0}\right)$ versus three months after training $\left(\mathrm{t}_{1}\right)$.

single relationship

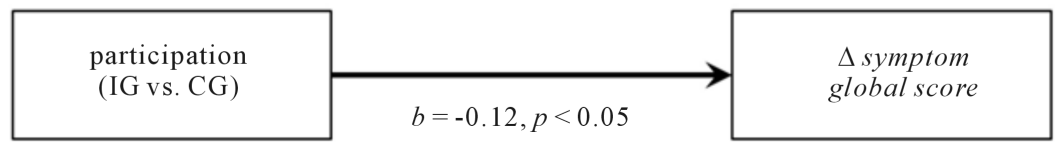

mediated relationship

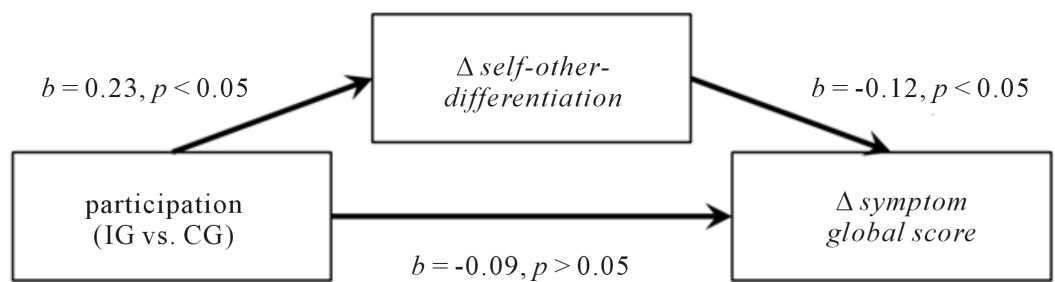

Figure 4. Mediation analysis with change $(\Delta)$ in self-other differentiation as the mediator of participation and change in the outcome variable global symptom score (which combines four scales from the symptom checklist).

thus indicating that the effects of the training on changes in the adjustment scores were partially mediated by changes in self-other differentiation. In both cases, these indirect effects were significant according to the Sobel test $(p<0.05)$. However, as shown by the regression coefficients as well as by $\kappa^{2}$ for the global symptom score $\left(\kappa^{2}=0.03, p<0.05\right)$, and for emotional irritation $\left(\kappa^{2}=0.03, p<0.05\right)$, these effects are rather small. 
single relationship

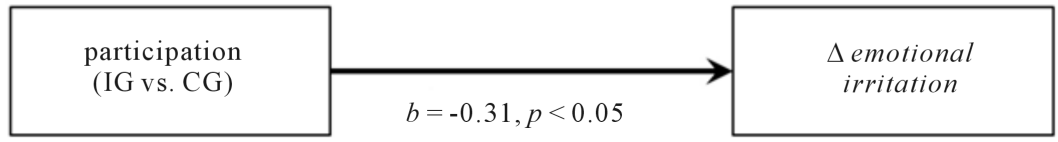

mediated relationship

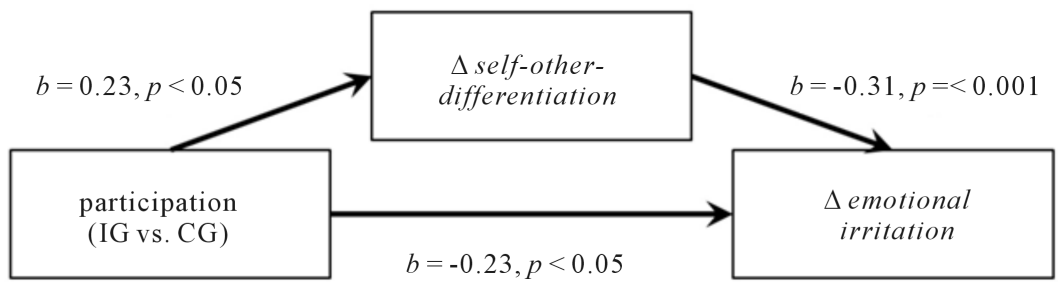

Figure 5. Mediation analysis with change $(\Delta)$ in self-other differentiation as the mediator of participation and change in the outcome variable emotional irritation.

\section{Discussion}

\subsection{Program Efficacy}

The results showed that the ability to differentiate between one's own emotions and the emotional situations of other people increased only to some extent though significantly in the intervention group compared with the control group. We believe that change was produced by the training's constant emphasis on focusing both on the emotional situation of the other person and on one's own emotional situation. This was followed by a slight increase in emotional competences, such as the ability to act empathically in a reflected way even in challenging emotional situations, as emotional self-other differentiation facilitated the handling of such emotional situations. Maladjustment symptoms such as irritation and psychosomatic symptoms decreased accordingly (Thoma et al., 2011). These changes, though significant, showed only small to medium effect sizes, which will be discussed below.

Analyses showed that our sample of nursing students displayed much lower scores on the maladjustment symptoms and higher scores in the competence self-ratings than expected. Although the curriculum of nursing training encompasses long periods of training on the job, the students obviously did not yet show the much higher levels of strain common in this field. A possible explanation for this could be that the students' recurring off-the-job training times significantly reduce the stress they experience. The resulting contrast between their own experience of low stress and the much higher stress levels of the full-time nurses with whom they work during their on-the-job-training time might in turn cause the students to overestimate their competences (stable internal attribution; Weiner, 1986). To enhance already strong competence ratings and reduce already low symptom ratings with high effect sizes is unlikely (ceiling and floor effect, respectively).

On a similar note, an interesting phenomenon occurred in that some of the effects were caused mostly by a negative change in the control group and only slight or no change in the intervention group. This can be interpreted as a buffering or preventive effect of the training against the well-known tendency of growing strain in the course of years on the job. The intervention group maintained their high competence and low maladjustment levels even during the strenuous on-the-job-training, while the control group began to decline to the normal and more common level of full-time nurses.

The general effect sizes reached only a small and medium level. We believe, however, that the effects are noteworthy for two reasons. First, effects greater than 0.20 are in fact clinically relevant (Kimber et al., 2007) and the significant training effects ranged from 0.22 to 0.39 . And second, these effects occurred even in a sample of unimpaired nursing novices with very low maladjustment symptoms at the pre measurement. It can therefore be expected that a sample with higher symptom scores (such as full-time nurses) would show an accordingly stronger decrease. Therefore, the current effect sizes probably underestimate the potential of the intervention which as it stands provides a buffering effect for trainees. 
Further studies are planned to evaluate the training with full-time workers, which requires the length of the training program to be shortened significantly. Focusing on the practical session, mostly on self-other differentiation exercises, and reducing the theoretical units might produce the same if not better results (see paragraph below).

\subsection{Mediation}

Results showed that the relation between participation in the training and the outcome variables of maladjustment were mediated by self-other differentiation. The very small effect sizes might indicate that the mediator is only one among several other important influencing factors, such as self-efficacy or participants' motivation during the training or sympathy toward the trainer. Of course, the low internal consistency of the measure most likely weakened the effect noticeably. Using alternative measures, such as the Emotional Contagion Scale (Doherty, 1997) as an inverted indicator for self-other differentiation, might produce more reliable results in further studies.

\subsection{Limitations and Prospects}

The major restriction of the study is of course the sample of nursing students, as discussed above. The validity of the program's effectiveness among full-time workers and in different professions (e.g., therapy or education) still needs to be tested. Furthermore, we used only two points of measurement and were therefore unable to evaluate the single modules of the program, which would ease the compilation of a shorter version. Finally, although the sample roughly represented the distribution of men and women in the field of nursing, it must be mentioned that $83 \%$ of the participants were female, which limits the validity of our results mainly to this gender.

\subsection{Conclusion}

While training and developing empathy "per se" also increases the risk of further developing the potential negative outcomes of empathy (maladjustment symptoms such as irritation, depressiveness, and burnout), training empathy by strengthening self-other differentiation can reduce and buffer the development of these symptoms. It seems plausible to integrate self-other differentiation not only as an assumption in the empathy definition but also as an essential part in empathy training programs. The concept of Nonviolent Communication can be used as a helpful technique to learn and practice the expression and reflection of self-other differentiated empathy.

\section{References}

Altmann, T., \& Roth, M. (2013). The Evolution of Empathy: From Single Components to Process Models. In C. Mohiyeddini, M. Eysenck, \& S. Bauer (Eds.), Handbook of Psychology of Emotions (pp. 171-188). New York: Nova Science Publishers.

Åström, S., Nilsson, M., Norberg, A., Sandman, P., \& Winbald, B. (1991). Staff burnout in Dementia Care: Relations to Empathy and Attitudes. International Journal of Nursing Studies, 28, 65-75. http://dx.doi.org/10.1016/0020-7489(91)90051-4

Baron, R. M., \& Kenny, D. A. (1986). The Moderator-Mediator Variable Distinction in Social Psychological Research: Conceptual, Strategic and Statistical Considerations. Journal of Personality and Social Psychology, 51, 1173-1182. http://dx.doi.org/10.1037/0022-3514.51.6.1173

Batson, C. D., \& Shaw, L. L. (1991). Encouraging Words Concerning the Evidence for Altruism. Psychological Inquiry, 2 , 159-168. http://dx.doi.org/10.1207/s15327965pli0202 17

Batson, C. D., Fultz, J., \& Schoenrade, P. A. (1987). Distress and Empathy: Two Qualitatively Distinct Vicarious Emotions with Different Motivational Consequences. Journal of Personality, 55, 19-39.

http://dx.doi.org/10.1111/j.1467-6494.1987.tb00426.x

Becker, B. J. (1988). Synthesizing Standardized Mean-Change Measures. British Journal of Mathematical and Statistical Psychology, 41, 257-278. http://dx.doi.org/10.1111/j.2044-8317.1988.tb00901.x

Berking, M., \& Znoj, H. (2008). Entwicklung und Validierung eines Fragebogens zur standardisierten Selbsteinschätzung emotionaler Kompetenzen (SEK-27) [Development and Validation of a Questionnaire for Standardized Self-Reports of Emotional Competences]. Zeitschrift für Psychiatrie, Psychologie und Psychotherapie, 56, 141-153.

http://dx.doi.org/10.1024/1661-4747.56.2.141 
Bragard, I., Etienne, A.-M., Merckaert, I., Libert, Y., \& Razavi, D. (2010). Efficacy of a Training on Medical Residents' Self-Efficacy, Stress to Communicate and Burnout: A Randomized Controlled Study. Journal of Health Psychology, 15, 1075-1081. http://dx.doi.org/10.1177/1359105310361992

Brunero, S., Lamont, S., \& Coates, M. (2010). Review of Empathy Education in Nursing. Nursing Inquiry, $17,65-74$. http://dx.doi.org/10.1111/j.1440-1800.2009.00482.x

Büssing, A., \& Perrar, K. M. (1992). Die Messung von Burnout: Untersuchung einer deutschen Fassung des Maslach Burnout Inventory (MBI-D) [Measurement of Burnout: Analysis of a German Version of the Maslach Burnout Inventory]. Diagnostica, 38, 328-353.

Butters, R. P. (2010). A Meta-Analysis of Empathy Training Programs for Client Populations. Doctoral Dissertation, Salt Lake City, UT: University of Utah. http://content.lib.utah.edu/u?/us-etd2,152303

Carré, A., Stefaniak, N., D’Ambrosio, F., Bensalah, L., \& Besche-Richard, C. (2013). The Basic Empathy Scale in Adults (BES-A): Factor Structure of a Revised Form. Psychological Assessment, 25, 679-691. http://dx.doi.org/10.1037/a0032297

Cohen, J. (1988). Statistical Power Analysis for the Behavioral Sciences. Hillsdale, NJ: Erlbaum.

Corcoran, K. J. (1989). Interpersonal Stress and Burnout: Unraveling the Role of Empathy. Journal of Social Behavior and Personality, 4, 141-144.

Davis, M. H. (1983). Measuring Individual Differences in Empathy: Evidence for a Multidimensional Approach. Journal of Personality and Social Psychology, 44, 113-126. http://dx.doi.org/10.1037/0022-3514.44.1.113

Decety, J., \& Jackson, P. L. (2006). A Social-Neuroscience Perspective on Empathy. Current Directions in Psychological Science, 15, 54-58. http://dx.doi.org/10.1111/j.0963-7214.2006.00406.x

Decety, J., \& Lamm, C. (2009). Empathy versus Personal Distress: Recent Evidence from Social Neuroscience. In J. Decety, \& W. Ickes (Eds.), The Social Neuroscience of Empathy (pp. 199-214). Cambridge, UK: MIT Press. http://dx.doi.org/10.7551/mitpress/9780262012973.003.0016

Derogatis, L. R. (1977). SCL-90-R, Administration, Scoring \& Procedures Manual-I for the R(evised) Version. Baltimore, MD: Self Published.

Doherty, R. W. (1997). The Emotional Contagion Scale: A Measure of Individual Differences. Journal of Nonverbal Behavior, 21, 131-154. http://dx.doi.org/10.1023/A:1024956003661

Duquette, A., Kérowc, S., Sandhu, B. K., \& Beaudet, L. (1994). Factors Related to Nursing Burnout: A Review of Empirical Knowledge. Issues in Mental Health Nursing, 15, 337-358. http://dx.doi.org/10.3109/01612849409006913

Franke, G. H. (1995). Die Symptom-Checkliste von Derogatis: SCL-90-R [The Symptom Checklist by Derogatis]. Göttingen: Beltz Test.

Gerdes, K. E., Segal, E. A., \& Lietz, C. A. (2010). Conceptualising and Measuring Empathy. British Journal of Social Work, 40, 2326-2343. http://dx.doi.org/10.1093/bjsw/bcq048

Henderson, A. (2001). Emotional Labor and Nursing: An Under-Appreciated Aspect of Caring Work. Nursing Inquiry, 8, 130-138. http://dx.doi.org/10.1046/j.1440-1800.2001.00097.x

Hoffman, M. L. (2000). Empathy and Moral Development: Implications for Caring and Justice. Cambridge, UK: Cambridge University Press. http://dx.doi.org/10.1017/CBO9780511805851

Hojat, M. (2007). Empathy in Patient Care: Antecedents, Developments, Measurements, and Outcomes. New York: Springer Science+Business Media.

Kellett, J. B., Humphrey, R. H., \& Sleeth, R. G. (2002). Empathy and Complex Task Performance: Two Routes to Leadership. The Leadership Quarterly, 13, 523-544. http://dx.doi.org/10.1016/S1048-9843(02)00142-X

Kimber, B., Sandell, R., \& Bremberg, S. (2007). Social and Emotional Training in Swedish Schools for the Promotion of Mental Health: An Effectiveness Study of 5 Years of Intervention. Health Education Research, 23, 931-940. http://dx.doi.org/10.1093/her/cyn040

Kohut, H. (1984). How Does Analysis Cure? Chicago, IL: University of Chicago Press. http://dx.doi.org/10.7208/chicago/9780226006147.001.0001

Kunyk, D., \& Olson, J. K. (2001). Clarification of Conceptualizations of Empathy. Journal of Advanced Nursing, 35, 317325. http://dx.doi.org/10.1046/j.1365-2648.2001.01848.x

Lamm, C., Batson, C. D., \& Decety, J. (2007). The Neural Substrate of Human Empathy: Effects of Perspective-Taking and Cognitive Appraisal. Journal of Cognitive Neuroscience, 19, 42-58. http://dx.doi.org/10.1162/jocn.2007.19.1.42

Lee, H. (2010). The Relationship between Emotional Intelligence and Emotional Labor and Its Effect on Job Burnout in Korean Organizations. PhD Dissertation, Minneapolis, MN: University of Minnesota. 
Long, E. C. J., Angera, J. J., \& Hakoyama, M. (2008). Transferable Principles from a Formative Evaluation of a Couples' Empathy Program. Journal of Couple \& Relationship Therapy, 7, 88-112. http://dx.doi.org/10.1080/15332690802106828

Marshall, W. L., Hudson, S. M., Jones, R., \& Fernandez, Y. M. (1995). Empathy in Sex Offenders. Clinical Psychology Review, 15, 99-113. http://dx.doi.org/10.1016/0272-7358(95)00002-7

Mohr, G., Müller, A., Rigotti, T., Aycan, Z., \& Tschan, F. (2006). The Assessment of Psychological Strain in Work Contexts: Concerning the Structural Equivalency of 9 Language Adaptations of the Irritation-Scale. European Journal of Psychological Assessment, 22, 198-206. http://dx.doi.org/10.1027/1015-5759.22.3.198

Preacher, K. J., \& Kelley, K. (2011). Effect Size Measures for Mediation Models: Quantitative Strategies for Communicating Indirect Effects. Psychological Methods, 16, 93-115. http://dx.doi.org/10.1037/a0022658

Preston, S. D., \& de Waal, F. B. M. (2002). Empathy: Its Ultimate and Proximate Basis. Behavioral and Brain Sciences, 25, $1-20$.

Rindermann, H. (2009). Emotionale-Kompetenz-Fragebogen: EKF [Emotional Competence Questionnaire]. Göttingen: Hogrefe.

Rogers, C. R. (1957). The Necessary and Sufficient Conditions of Therapeutic Personality Change. Journal of Consulting Psychology, 21, 95-103. http://dx.doi.org/10.1037/h0045357

Rosenberg, M. B. (1999). Nonviolent Communication: A Language of Compassion. Del Mar, CA: PuddleDancer Press.

Rosenberg, M. B. (2012). Living Nonviolent Communication. Boulder, CO: Sounds True.

Rosenberg, M. B., \& Molho, P. (1998). Nonviolent (Empathic) Communication for Health Care Providers. Haemophilia, 4, 335-340. http://dx.doi.org/10.1046/j.1365-2516.1998.440335.x

Singer, T. (2006). The Neuronal Basis and Ontogeny of Empathy and Mind Reading: Review of Literature and Implications for Future Research. Neuroscience and Biobehavioral Reviews, 30, 855-863. http://dx.doi.org/10.1016/j.neubiorev.2006.06.011

Sobel, M. E. (1982). Asymptotic Confidence Intervals for Indirect Effects in Structural Equation Models. Sociological Methodology, 13, 290-312. http://dx.doi.org/10.2307/270723

Steins, G., \& Wicklund, R. A. (1993). Zum Konzept der Perspektivübernahme: Ein kritischer Überblick [On the Concept of Perspective Taking: A Critical Overview]. Psychologische Rundschau, 44, 226-239.

Stepien, K. A., \& Baernstein, A. (2006). Educating for Empathy: A Review. Journal of General Internal Medicine, 21, 524530. http://dx.doi.org/10.1111/j.1525-1497.2006.00443.x

Thoma, P., Zalewski, I., von Reventlow, H. G., Norra, C., Juckel, G., \& Daum, I. (2011). Cognitive and Affective Empathy in Depression Linked to Executive Control. Psychiatry Research, 189, 373-378.

http://dx.doi.org/10.1016/j.psychres.2011.07.030

Thomas, J. (2013). Association of Personal Distress with Burnout, Compassion Fatigue, and Compassion Satisfaction among Clinical Social Workers. Journal of Social Service Research, 39, 365-379. http://dx.doi.org/10.1080/01488376.2013.771596

Weiner, B. (1986). An Attributional Theory of Motivation and Emotion. New York: Springer. http://dx.doi.org/10.1007/978-1-4612-4948-1 